\title{
A PERSONA LÍRICO-ELEGÍACA DE ENCÓLPIO NO SATYRICON DE PETRÔNIO
}

\author{
Júlia Batista Castilho de Avellar ${ }^{1 \star}$ \\ Universidade Federal de Minas Gerais/ CNPq
}

\begin{abstract}
This paper investigates the presence of tópoi and models of Latin lyric-elegiac poetry in two episodes of Petronius's Satyricon: the breaking of Encolpius and Giton and the love relationship between Encolpius/ Polyaenus and Circe. In the first episode, the focus will be on the narrator's poetic inserts, and, in the second one, on prose narrative. We seek to identify and analyse some allusions to lyric-elegiac literary tradition in these episodes, to verify how their presence causes the parody of the models and, in this way, to see how this resource produces a metaliterary discussion. Furthermore, we intend to show that, more than a "mythomaniac narrator" (Conte, 1996), Encolpius presents himself as a literomaniac narrator, assuming various personae throughout the narrative (not only an epic persona, but also a lyric-elegiac one).

KEYWORDS: Latin novel; Petronius; Satyricon; Latin lyric-elegiac poetry; intertextuality.
\end{abstract}

\footnotetext{
^juliabcavellar@gmail.com

${ }^{1}$ Mestranda do Programa de Pós-Graduação em Estudos Literários da Faculdade de Letras da UFMG. O presente trabalho foi realizado com apoio do CNPq, Conselho Nacional de Desenvolvimento Científico e Tecnológico - Brasil. Ele resultou das pesquisas feitas durante a disciplina "Literatura, História e Cultura na Antiguidade e na Idade Média: o romance latino”, ministrada, no primeiro semestre de 2014, pela Profa. Dra. Sandra Bianchet, a quem muito agradeço pela leitura cuidadosa e enriquecedores comentários e sugestões.
} 


\section{Introdução}

Satyricon, de Petrônio, ${ }^{2}$ é uma obra que levanta diversas questões quanto à vinculação a um gênero literário. Alguns o consideraram uma paródia dos romances gregos ou da poesia épica, outros destacaram sua proximidade com a sátira (em especial a sátira menipeia, que explora a combinação entre prosa e verso) ou então com o mimo, bastante popular na época do Império. ${ }^{3}$ Por sua vez, as estratégias narrativas, a predominância da prosa e o caráter ficcional possibilitam sua aproximação ao gênero do romance, ainda que não estivesse contemplado na poética clássica. ${ }^{4}$ A esse respeito, destaca-se o fato de o romance "incorporar, com facilidade, temas e técnicas próprias de outros gêneros, transformando-os em romanescos, num autêntico processo gramatofágico". 5

Ora, uma das riquezas do Satyricon consiste justamente em agregar tópoi dos mais variados gêneros literários e empreender uma prática, muitas vezes alusiva, que culmina com a paródia dos modelos da "grande literatura". Sob esse aspecto, é interessante pensar no sentido de satura/ satira sugerido pelo título Satyricon: ${ }^{6}$ a obra constitui uma verdadeira "mistura", não só de trechos em prosa e verso, mas, sobretudo, de elementos de diversos gêneros e de inúmeros modelos literários. Por meio desse procedimento, "o autor usa a narrativa para falar sobre os gêneros e, através

\footnotetext{
${ }^{2}$ Embora de autoria e datação incertas, a maior parte dos estudiosos atribui a obra a um Petronius, elegantiae arbiter da corte de Nero, cuja menção é feita por Tácito (Annales, 16, 18-20), e situa sua data de escrita em torno do ano de 65 d. C. Para mais detalhes acerca dessas questões, consultar Leão, 2006, p. 227-229; Bianchet, 2004, p. 7-11.

${ }^{3}$ Cf. Konstan, 1994, p. 113-114.

${ }^{4}$ Segundo Brandão (2005, p. 56), apenas nos primeiros duzentos anos de nossa era se impõe, como gênero literário, a narrativa de ficção em prosa, confundindo a fronteira que, ainda na época de Aristóteles e pelo menos nos três séculos subsequentes, circunscrevera praticamente a literatura à forma versificada. Embora a maior parte das discussões do estudioso refira-se ao romance grego, elas podem ser facilmente estendidas à produção latina.

${ }^{5}$ Cf. Brandão, 2005, p. 160. Brandão também destaca que o romance não depende exclusivamente de um único gênero, nem surge apenas da fusão de alguns gêneros determinados, mas dialoga livremente com o conjunto da tradição literária (p. 141).

${ }^{6}$ Além da acepção de satural satira, o título pode se relacionar ao termo satyros ("debochado", "irreverente", ou mesmo a personagem dos sátiros) e a satureum, planta afrodisíaca e alucinógena, que aparece três vezes nos episódios iniciais da obra (Sat. 8, 4; 20, 7; 21, 1). Cf. Bianchet, 2012, p. 112.
} 
deles, discute literatura fazendo literatura".

Para isso, contribui imensamente o fato de o narrador em primeira pessoa, Encólpio, frequentemente aproximar de situações literárias aquilo que viveu como personagem, de modo a se identificar com papéis heroicos e personagens míticas. Ou seja, suas aventuras como personagem são inocentemente exaltadas e vinculadas à literatura elevada por um outro Encólpio, o scholasticus, ${ }^{8}$ que se constitui como aquilo que Conte denomina um "narrador mitomaníaco, isto é, Encólpio em sua idealizada paixão pelo mito literário". 'Exatamente por se tratar de um "narrador dramatizado", isto é, "aquele que se apresenta no texto como diferente do poeta ou escritor e, nessa condição, exerce a função diegética", ${ }^{10}$ é que se instaura na narrativa petroniana a ironia, resultante da distância entre o hidden author (autoimagem implícita que Petrônio cria como autor de seu texto) e o narrador mitomaníaco. ${ }^{11}$ Dessa forma, ao longo do Satyricon, a aproximação do narrador a heróis épicos, bem como a aproximação da própria narrativa ao gênero épico, revela como resultado, na maior parte das vezes, um caráter irônico. Ao serem aludidos tópoi da épica, citados trechos ou nomes de heróis épicos ou empregados procedimentos característicos desse gênero, Petrônio realiza, na verdade, uma inversão da fonte assumida como modelo,

\footnotetext{
${ }^{7}$ Cf. Bianchet, 2012, p. 112.

${ }^{8}$ Cf. Conte, 1996, p. 2: “O jovem Encólpio é um pequeno aventureiro que ganha a vida perambulando sem rumo de um lugar para outro; mas o ritmo da narrativa [...] é continuamente refreado pelas reflexões literárias de outro Encólpio, o scholasticus, vítima de suas próprias experiências literárias, o qual ingenuamente exalta a si mesmo ao se identificar com papéis heroicos entre os de grandes personagens míticas e literárias do passado" (Young Encolpius is a petty adventurer who gets his living by wandering aimlessly from place to place; but the pace of the action [...] is continually slowed down by the literary reflections of another Encolpius, the scholasticus, victim of his own literary experiences, who naively exalts himself by identifying with heroic roles among the great mythical and literary characters of the past. - trad. nossa). O estudioso investiga, por exemplo, a comparação de Encólpio com Aquiles e com Eneias no episódio em que Ascilto lhe toma Gitão. ${ }^{9}$ Cf. Conte, 1996, p. 3: "Mythomaniac narrator", that is, Encolpius in his romanticizing infatuation with literary myth (trad. nossa).

${ }^{10}$ Cf. Brandão, 2005, p. 105-106.

${ }^{11}$ Cf. Conte, 1996, p. 24: "A sofisticada forma narrativa do romance petroniano explora exatamente a clara distinção entre autor e narrador. A ironia é gerada em função da disparidade entre os pontos de vista ativados na narrativa" (The sophisticated narrative form of the Petronian novel plays precisely on the clear distinction between author and narrator. Irony is generated as a function of the disparity between the points of view activated in the narrative. - trad. nossa).
} 
de modo a parodiá-la e, assim, promover também um distanciamento em relação à mesma. Nesse sentido, enquanto Encólpio vê a si mesmo através dos mitos, o hidden author, juntamente com o leitor, ${ }^{12}$ pode vê-lo de fora, de forma que os elementos sublimes da tradição literária adquirem um caráter de "excesso melodramático", que promove sua inversão paródica.

Ora, observa-se que, em geral, as análises do Satyricon tendem a privilegiar a aproximação do narrador e de episódios da obra ao gênero épico, remarcando o caráter paródico da apropriação de seus elementos. Este estudo, por sua vez, busca investigar em que medida a obra evoca também modelos da poesia lírico-elegíaca e se os subverte paródica e ironicamente. Assim, pretende-se identificar no Satyricon alguns dos tópoi característicos do gênero ${ }^{13}$ e examinar de que modo a sua presença contribui para a reflexão metaliterária efetuada na obra. Para tal, serão analisadas as relações com o gênero lírico-elegíaco em dois tipos diferentes de manifestações do narrador Encólpio: as inserções poéticas no episódio de separação de Encólpio e Gitão e a narrativa em prosa no episódio de Circe.

\section{A persona lírico-elegíaca de Encólpio}

Após os episódios da Cena Trimalchionis, opera-se uma mudança notável na figura de Encólpio: o narrador em primeira pessoa, que até então expressara em prosa sua percepção dos fatos, passará a compor também poemas, inseridos ao longo da narrativa (no episódio da perda de Gitão para Ascilto, no episódio de Circe e no episódio de Enótia). Isso ocorre, ironicamente, quando surge no enredo uma nova personagem, o

\footnotetext{
${ }^{12}$ Para a percepção da ironia, no entanto, é necessária a colaboração de um leitor que atenda a certos requisitos, como perspicácia e educação literária adequada (cf. Conte, 1996, p. 35), isto é, um "leitor gramatofágico", capaz de reconhecer e identificar as referências literárias (cf. Brandão, 2005, p. 179).

${ }^{13}$ A esse respeito, é conveniente recordar que predominava na Antiguidade uma poética da alusão, e que é sobretudo na utilização dos "tópoi" que se revela a originalidade do poeta: a seleção, a expressão e a combinação deles oferecem possibilidades inesgotáveis de soluções imprevistas dentro do uso tradicional, chegando até a transgressões desse uso (cf. Achcar, 1994, p. 29). Sob essa perspectiva, a pertinência genérica de um poema resultava do repertório de lugares-comuns e da maneira de organizá-los no texto (p. 18). Giangrande (1991, p. 61), ademais, informa que os "elegíacos romanos construíram seus poemas segundo um procedimento de mosaico" (i poeti elegiaci romani costruirono $i$ loro carmi con un procedimento "mosaikarting”, a mosaico. - trad. nossa), combinando vários tópoi da poesia helenística.
} 
velho poeta Eumolpo, diversas vezes criticado por Encólpio justamente por não ser capaz de conter seus versos e, além disso, declamar poemas a todo tempo. Nesse sentido, ele pode ser aproximado do poeta uesanus mencionado na Epistula ad Pisones horaciana, o qual, em seu delírio de inspiração, "arrota versos sublimes e vagueia", ${ }^{14}$ afugenta os ouvintes e, quando os agarra, não mais lhes dá sossego. ${ }^{15}$ Essa caracterização fica evidente, por exemplo, quando Eumolpo é apedrejado por seus ouvintes após recitar um poema de assunto épico com versos inadequadamente no metro jâmbico, ${ }^{16}$ quando Encólpio denomina de doença a frequente produção de versos por Eumolpo ${ }^{17}$ e quando solicita que Eumolpo os poupe de ouvir os seus versos. ${ }^{18}$

Assim, diante do exemplo de Eumolpo, também Encólpio irá compor poemas. Em diversos momentos, seus versos apresentarão tópoi da poesia lírico-elegíaca, e o narrador assumirá uma persona poética de amante elegíaco. Exemplo disso são os versos feitos em ocasião da noite de amores com Gitão, quando se mencionam as carícias dos amantes e a

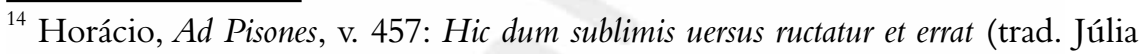
Avellar et alii, p. 49).

${ }^{15}$ Horácio, Ad Pisones, v. 472-476: Certe furit, ac uelut ursus,/ obiectos caueae ualuit si frangere clatros,/ indoctum doctumque fugat recitator acerbus;/ quem uero arripuit, tenet occiditque legendo,/ non missura cutem nisi plena cruoris hirudo. - "Decerto está louco e, assim como um urso,/ que teve a força para romper as grades colocadas diante da jaula,/ o recitador acerbo afugenta o indouto e o douto./ Em verdade, aquele que ele agarrou, prende e mata lendo;/ o sanguessuga não há de soltar a pele senão pleno de sangue" (trad. Júlia Avellar et alii, p. 49 e 51).

${ }^{16}$ Petrônio, Satyricon, 90, 1: Ex is, qui in porticus spatiabantur, lapides in Eumolpum recitantem miserunt. - "Entre aqueles que passeavam nos pórticos, alguns jogaram pedras em Eumolpo, enquanto ele recitava seu poema" (trad. Sandra Bianchet, p. 157; todas as traduções do Satyricon aqui citadas são, como será indicado a cada vez, ou de Sandra Bianchet ou, em número menor de casos, nossas).

${ }^{17}$ Petrônio, Satyricon, 90, 3: Rogo inquam quid tibi uis cum isto morbo? Minus quam duabus horis mecum moraris, et saepius poetice quam humane locutus es. Itaque non miror, si te populus lapidibus persequitur. - "Responda-me, o que você quer com esta sua doença? Você está comigo há menos de duas horas e conversou mais vezes como poeta do que como gente. É por isso que eu não me admiro do povo te perseguir com pedras" (trad. S. Bianchet, p. 159).

${ }^{18}$ Petrônio, Satyricon, 93, 3: Hoc est, inquam, quod promiseras, ne quem hodie uersum faceres? Per fidem, saltem nobis parce, qui te numquam lapidauimus. - "É isto que você tinha prometido, que hoje não faria nem um verso sequer? Tenha paciência, poupe pelo menos a nós, que nunca apedrejamos você” (trad. S. Bianchet, p. 165). 
transferência das almas por meio dos beijos:

Que noite aquela, deuses e deusas, que leito macio! Ferventes nos unimos e as almas errantes nós transferimos de um lábio a outro. Adeus, aflições mortais. E assim comecei a morrer. ${ }^{19}$

O vocabulário empregado no poema é tipicamente lírico-elegíaco (o diminutivo labellis; o termo calentes, que aponta para o tópos de "arder de amor"; o termo curae, usado para as dores do amor não correspondido). Além disso, a celebração dos amores, marcada pelo tom exclamativo dos versos iniciais, aproxima-se dos primeiros versos da elegia II, 15 de Propércio, outro exemplo do tópos do sucesso do eu-poético na conquista de uma noite amorosa:

Ó sou feliz! Ó noite radiante! Ó tu, leito ditoso graças aos meus gozos!

Que palavras trocadas sob o fogo aceso, que imensa luta ao se apagar a luz!

Entre a nudez dos seios combateu comigo e às vezes resistiu retendo a túnica.

Com seus lábios abriu meus olhinhos de sono e me disse "Ah, molenga, estás dormindo?"

Como nos abraçamos num enlace! Quanto demorou-se em teus lábios o meu beijo!

[‥]

Como as folhas que caem das guirlandas secas

e nadam salpicadas sobre as taças

somos nós; pois se agora tanto suspiramos, o amanhã talvez feche nosso Fado. ${ }^{20}$

\footnotetext{
${ }^{19}$ Petrônio, Satyricon, 79, 8: Qualis nox fuit illa, di deaeque,/ quam mollis torus! Haesimus calentes/ et transfudimus hinc et hinc labellis/ errantes animas. Valete curae/ mortales. Ego sic perire coepi (trad. nossa).

${ }^{20}$ Propércio, Elegias, II, 15, v. 1-10 e v. 51-4: O me felicem! O nox mihi candida! Et o tu/ lectule deliciis facte beate meis!/ Quam multa apposita narramus uerba lucerna,/ quantaque sublato lumine rixa fuit!/ Nam modo nudatis mecum est luctata papillis,/ interdum tunica duxit operta moram./ Illa meos somno lapsos patefecit ocellos/ ore suo et dixit "Sicine, lente, iaces?"/ Quam uario amplexu mutamus bracchia! Quantum/ oscula sunt labris nostra morata tuis! [...] Ac ueluti folia arentis liquere corollas,/ quae passim calathis strata natare uides,/ sic nobis, qui nunc magnum spiramus amantes,/ forsitan includet crastina Fata dies (trad.
} 
Nos dois poemas, são referidos os beijos, abraços e enlaces entre os amantes, num tom de exaltação do amor. Igualmente, percebe-se que ambos terminam com uma reflexão sobre a iminência morte (perire coepi, no Satyricon, e includet crastina Fata dies, na elegia properciana), de modo a aludir ao tema do carpe diem: enquanto ainda é tempo, deve-se fruir a noite de amores, pois o futuro é incerto. Porém, o último verso do poema de Encólpio, se considerado no âmbito geral da obra, ganha nova significação, mediante sua inversão paródica. O que no poema properciano e na tradição do carpe diem consiste no fim da vida humana, no contexto do Satyricon, por outro lado, parece designar metaforicamente, por meio de uma antecipação, a morte que incidirá sobre o narrador: sua impotência sexual nas futuras relações com Circe. ${ }^{21}$

Isso parece corroborar a percepção de Connors, segundo a qual as inserções poéticas de Encólpio instauram um contraste entre seus versos, que expressam uma imagem idealizada do amor, e a narrativa em prosa, que revela eventos vulgares e ridículos: o narrador/ poeta "encontra-se em situações em que a satisfação amorosa parece possível; ele celebra em verso, para, pouco depois, narrar em prosa a frustração de suas esperanças". Desse modo, o modelo elegíaco evocado no poema de Encólpio é refutado na sequência em prosa, cujos eventos culminarão na perda de Gitão e no fim das celebrações: "Não tenho motivo para me felicitar, pois, quando eu, relaxado pelo vinho, afrouxei minhas mãos bêbadas e soltei Gitão, Ascilto, o inventor de toda a ofensa, roubou durante a noite meu rapazinho de mim, transferiu-o para sua cama". ${ }^{23}$

A esse respeito, Connors ${ }^{24}$ destaca ainda que diversos termos utilizados no poema, se lidos à luz da sequência narrativa em prosa,

Guilherme Flores, p. 125 e 127).

${ }^{21} \mathrm{O}$ narrador se refere à impotência como morte e funerais daquela parte de seu corpo que faltara às suas funções, aspectos que serão desenvolvidos mais detalhadamente no presente artigo na subsequente discussão do episódio de Circe. É interessante notar que, a partir da noite de amores com Gitão, em que Encólpio "começou a morrer", o narrador-personagem não mais será capaz de se envolver sexualmente, sofrendo de impotência nos relacionamentos seguintes.

${ }^{22}$ Cf. Connors, 1998, p. 68: Encolpius finds himself in situations where erotic satisfaction seems possible; he celebrates in verse, only to narrate his dashed hopes in prose (trad. nossa). ${ }^{23}$ Petrônio, Satyricon, 79, 8-9: Sine causa gratulor mihi. Nam cum solutus mero remisissem ebrias manus, Ascyltos, omnis iniuriae inuentor, subduxit mihi nocte puerum et in lectum transtulit suum (trad. S. Bianchet, p. 139).

${ }^{24}$ Cf. Connors, 1998, p. 69. 
adquirem novos significados e revelam-se ambíguos. O verbo transfundo, por exemplo, que no poema refere-se à transferência das almas de uma boca para outra, parece antecipar a transferência de Gitão para Ascilto. O termo errantes, por sua vez, usado para caracterizar as almas dos amantes, pode ser estendido, na narrativa em prosa, ao próprio Encólpio, que, após perder Gitão, vagueia sem rumo e infeliz. Além disso, na medida em que pode significar também "instável”, "incerto", aponta ainda para a instabilidade da amizade, tema explorado em outra inserção poética de Encólpio:

A amizade se conserva até quando convém;

a peça no tabuleiro exerce móvel tarefa.

Enquanto a Fortuna é constante, mostrais a face, amigos; quando sucumbe, virais a cara em torpe fuga. ${ }^{25}$

O poema contém uma reflexão sobre a mutabilidade da sorte (fortuna) e a vincula à fuga ( $f u g a)$ dos amigos, que permanecem enquanto a situação é favorável. ${ }^{26}$ Observe-se, por exemplo, o jogo de palavras entre uultum seruatis e uertitis ora: a alteração dos termos usados para designar a face dos amigos corresponde a uma mudança na própria atitude deles (inclusive, as ações designadas pelos verbos se opõem), o que revela, na verdade, a mudança da Fortuna (haeret, cecidit). É interessante notar, além disso, a ambiguidade de mobile, que, por um lado, refere-se à peça que se movimenta no tabuleiro, mas também aponta para a instabilidade da Fortuna, que é móvel. Esse é um tópos bem presente na elegia de exílio ovidiana, que aborda continuamente o tema da amizade e lamenta a fuga (fugiunt) dos amigos após o banimento:

Enquanto a Fortuna ajuda e sorri com rosto sereno, tudo segue o poder inabalado.

Mas tão logo troveja, fogem e ninguém reconhece quem há pouco era rodeado por bandos de companheiros. ${ }^{27}$

\footnotetext{
${ }^{25}$ Petrônio, Satyricon, 80, 9: Nomen amicitiae, sic, quatenus expedit, haeret;/ calculus in tabula mobile ducit opus./ Dum fortuna manet, uultum seruatis, amici;/ cum cecidit, turpi uertitis ora fuga (trad. nossa).

${ }^{26}$ Esses tópoi da súbita mudança da sorte e da perda dos amigos também são discutidos nos episódios da Cena Trimalchionis, durante as conversas entre os libertos (Sat. 41, 10; 42, 3-4; 43, 6; 45, 2).

${ }^{27}$ Ovídio, Tristia, I, 5, 27-30: Dum iuuat et uultu ridet Fortuna sereno,/ indelibatas cuncta sequuntur opes; / at simul intonuit, fugiunt nec noscitur ulli/ agminibus comitum qui modo cinctus erat (trad. nossa).
} 
Além da semelhança temática e lexical, há a métrica: Encólpio compõe o seu poema também em dísticos elegíacos. A isso se soma o fato de, na sequência em prosa, o narrador se considerar justamente um exilado (exul): "Será que eu escapei a um julgamento, enganei a arena, matei meu anfitrião, para, entre esses títulos de audácia, acabar abandonado como um indigente, um exilado, numa hospedaria de uma cidade grega?". ${ }^{28}$ Ora, nesse sentido, o narrador Encólpio, que antes assumira uma persona elegíaca de amante, poderia revelar também uma persona elegíaca de exilado.

A esse respeito, convém observar que o tópos da instabilidade dos amigos, que permanecem apenas durante os tempos de prosperidade, há muito já se fazia presente na tradição grega, destacando-se, nesse sentido, a produção elegíaca de Teógnis de Mégara (séculos VI-V a. C.), ou melhor, dos poemas reunidos sob o nome de Theognidea, uma vez que a atribuição das elegias é às vezes incerta. Além das passagens em que são feitas reflexões acerca da pouca fidelidade dos amigos, ${ }^{29}$ também estão presentes nessas elegias os tópoi da instabilidade ${ }^{30}$ e da perda dos amigos

${ }^{28}$ Petrônio, Satyricon, 81, 3: Effugi iudicium, harenae imposui, hospitem occidi, ut inter
audaciae nomina mendicus, exul, in deuersorio Graecae urbis iacerem desertus? (trad. S. Bianchet, p. 141)

${ }^{29}$ Teógnis, Theognidea, aqui sempre citado na tradução de Glória Onelley: "Não comuniques inteiramente a todos os amigos os teus atos; entre muitos, certamente poucos têm um coração fiel”. (v. 73-74, p. 128); "Encontrarás poucos homens, Polipaides, que se tornam companheiros fiéis nos momentos difíceis, amigos que, comungando no mesmo ânimo, ousariam partilhar igualmente dos bons e dos maus momentos”. (v. 79-82, p. 128); "Quando a infelicidade sobrevém a um homem, ninguém quer ser seu amigo, nem daquele que saiu do mesmo ventre, Cirno". (v. 299-300, p. 134); "Se eu estou feliz, tenho muitos amigos; mas se algo terrível me acontece, poucos têm o coração fiel”. (v. 697-698, p. 143); "Entre os meus amigos, se algum vir que eu sofro algo terrível vira a cara sem querer verme; mas se um bem me chega de algum lugar, aqueles que raramente acontecem a um homem, recebo muitos abraços e demonstrações de amizade". (v. 857-860, p. 147); "De fato, se és rico, tens muitos amigos, se és pobre, poucos, e já não és mais igualmente um homem de bem" (v. 929-930, p. 148).

${ }^{30}$ Teógnis, Theognidea: "E naturalmente cumprem uma coisa: do mal nasce o bem e do bem, o mal; o homem pobre enriquece repentinamente, e aquele que possui muitas coisas subitamente perde tudo, em uma só noite; o sábio falha, a glória acompanha muitas vezes o insensato e, embora seja inferior, obtém honra" (v. 661-666, p. 142). 
na situação de exílio. ${ }^{31}$

Por sua vez, o episódio dos amores entre Circe e Polieno/ Encólpio (Sat. 126-132) parece aludir ao modelo épico homérico. Connors, ${ }^{32}$ como boa parte da crítica, destaca inúmeros elementos que permitem o reconhecimento do intertexto homérico: o nome de Circe, seu comportamento sedutor, sua apresentação a partir de termos de referência homéricos, ainda que para se distinguir do modelo; ${ }^{33}$ a adoção, por Encólpio, do nome Polieno, que significa "aquele que conta muitas histórias" ou "aquele que é assunto de muitas histórias", um dos epítetos de Odisseu (polýainos, Il. 9, 673; Il. 10, 544; Il. 11, 430; Od. 12, 184); a inserção de versos épicos comparando os abraços de Encólpio e Circe (Sat., 127, 9) ao hieròs gámos de Zeus e Hera no Monte Ida na Ilíada (14, 343-51).

Não obstante a presença de modelo e intertexto épicos, o episódio também revela proximidades com o gênero lírico-elegíaco, na medida em que o relacionamento amoroso entre Encólpio/ Polieno e Circe parece pautar-se no código elegíaco. Uma primeira aproximação possível consiste na presença de uma escrava como intermediária entre os amantes. Bastante comum na poesia amorosa, o tópos das ancillae caracterizava-se pelo fato de as amas e as escravas desempenharem "um papel crucial no fazer surgirem relações amorosas entre jovens e moças, desde a idade helenística até o período imperial”. ${ }^{34}$ Ora, no Satyricon, é exatamente a escrava Críside que irá mediar o encontro entre Circe e Polieno, uma vez que revela a Encólpio/ Polieno o interesse de sua dona por ele e, a seguir, a leva até a plantação de plátanos combinada para o encontro entre os dois: "Sem demorar muito, ela [Críside] trouxe sua dona para fora do esconderijo e colocou a meu lado uma mulher mais perfeita do que todas as obras de arte". 35

${ }^{31}$ Teógnis, Theognidea: "Ninguém é amigo e companheiro fiel de um exilado; isso é mais penoso que o exílio" (v. 209-210, p. 131).

${ }^{32}$ Cf. Connors, 1998, p. 39-43.

${ }^{33}$ Petrônio, Satyricon, 127, 6: "Ita", inquit, "non dixit tibi ancilla mea Circen me uocari? Non sum quidem Solis progenies, nec mea mater, dum placet, labentis mundicursum detinuit”. - "O quê? Minha escrava não disse a você que me chamo Circe? Não sou a filha do Sol, é verdade, nem minha mãe, embora o desejasse, conseguiu deter o curso dos ágeis astros" (trad. S. Bianchet, p. 247).

${ }^{34}$ Cf. Giangrande, 1991, p. 79: La "nutrix" [...] e l'“ancilla” [...] giocavano un ruolo cruciale nel far nascere rapporti erotici tra giovinetti e fanciulle, da prima dell'età ellenistica fino al periodo imperiale (trad. nossa).

${ }^{35}$ Petrônio, Satyricon, 126, 13: Nec diu morata dominam producit e latebris, laterique meo applicat mulierem omnibus simulacris emendatiorem (trad. S. Bianchet, p. 243). 
Igualmente, após o primeiro evento de impotência sexual de Encólpio/ Polieno, é também a escrava que servirá de mediadora e levará a mensagem de sua dona ao amante: "No entanto, Críside entrou em meu quarto e entregou-me uma carta de sua dona" ${ }^{36}$ Além disso, ela aconselhará Encólpio/ Polieno a acalmar Circe e tornará possível um segundo encontro entre eles: "Apenas escreva de volta a minha dona muito docemente e devolva a ela a razão de viver, num sincero ato humanitário". ${ }^{37} \mathrm{O}$ conhecimento da escrava da amada, para que ela possa auxiliar na conquista, é um dos preceitos do magister amoris da Ars Amatoria ao amante elegíaco:

Mas antes cuida de conhecer a escrava da moça a se conquistar; ela facilitará teu acesso.

Afiança que seja próxima dos pensamentos de sua senhora e cúmplice não pouco fiel nos jogos secretos. ${ }^{38}$

Ademais, é interessante notar que os codicillos trocados por Encólpio/ Polieno e Circe sob o intermédio da escrava aproximam-se das tabuinhas usadas para a comunicação entre os amantes elegíacos, também pela mediação de uma escrava, constituindo outro tópos elegíaco:

Que a cera vertida nas lisas tabuinhas toque-lhe fundo, que a cera primeiro parta cúmplice de teu ânimo; que ela leve tuas meiguices e palavras imitadas dos amantes; e acresce, sejas quem for, não pequenos rogos. ${ }^{39}$

É importante observar, no entanto, que, embora a elegia amorosa

\footnotetext{
${ }^{36}$ Petrônio, Satyricon, 129, 3: Cubiculum autem meum Chrysis intrauit, codicillosque mihi dominae suae reddidit (trad. S. Bianchet, p. 251).

${ }^{37}$ Petrônio, Satyricon, 129, 11: Rescribe modo blandius dominae, animumque eius candida humanitate restitue (trad. S. Bianchet, p. 251).

${ }^{38}$ Ovídio, Ars Amatoria, I, 351-354: Sed prius ancillam captandae nosse puellae/ Cura sit; accessus molliet illa tuos./ Proxima consiliis dominae sit ut illa uideto,/ Neue parum tacitis conscia fida iocis (trad. nossa). É interessante observar que esse tópos elegíaco da troca de cartas entre amantes, preceituado na Ars Amatoria, foi explorado literariamente e posto em prática também nas Heroides de Ovídio, visto que as epístolas 16 a 21, que podem ser lidas em pares, são cartas de três amantes seguidas pelas respostas de suas respectivas amadas - Páris e Helena, Leandro e Hero e Acôncio e Cídipe. ${ }^{39}$ Ovídio, Ars Amatoria, I, 435-38: Cera uadum tempte, rasis infusa tabellis,/ cera tuae primum conscia mentis eat/ blanditias ferat illa tuas imitataque amantum/Verba, nec exiguas, quisquis es, adde preces (trad. nossa).
} 
tenha ambiência predominantemente urbana, de modo a apresentar a "vida urbana mundana e refinada dos apaixonados elegíacos típicos", ${ }^{40}$ no Satyricon, os amores de Circe e Polieno irão se desenrolar em um ambiente rural, espécie de locus amoenus, que muito se aproxima da tradição bucólica. Isso se evidencia pela inserção poética de Encólpio/ Polieno em hexâmetros, para descrever um lugar apropriado para o amor:

O plátano movente espalhara sombras de verão, também Dafne de frutos cingida e os ciprestes trementes, também os pinheiros podados em torno com seus cimos trepidantes. Entre árvores, brincava espumoso riacho com águas errantes e agitava as pedrinhas com queixoso fluxo.

Lugar apropriado para o amor: é testemunha o rouxinol silvestre, e Procne das cidades, que, soltos em torno das ervas e tenras violetas, ornavam os campos com seu canto. ${ }^{41}$

No poema, são referidos diversos tipos de árvores, pássaros e até mesmo um riacho, elementos que compõem o cenário bucólico. Porém, por mais agradável que seja o local, há vários termos da descrição que apontam para frustrações amorosas: o loureiro é referido pelo nome de Daphne, de modo a evocar os amores malfadados de Dafne e Apolo; o termo cupressus remete à decepção de Apolo com a morte de seu amado Ciparisso; o riacho tem águas queixosas (querulo...rore); o platanus mobilis e as aquis errantibus evocam conotações de instabilidade e mutabilidade. Para Connors, ${ }^{42}$ tais frustrações aludiriam à frustração de Encólpio na realização dos atos amorosos.

Apesar desses aspectos bucólicos, há diversos outros elementos que aproximam o romance de Circe e Encólpio/ Polieno ao amor elegíaco, como a submissão do amante à sua amada, o que se observa já no primeiro diálogo entre eles: "Então, eu disse: 'Muito pelo contrário, eu é que peço a você, em nome de sua beleza, que não me desdenhe e admita este forasteiro entre seus admiradores. Você irá descobrir que sou dedicado, se permitir que

\footnotetext{
${ }^{40}$ Cf. Trevizam, 2003, p. 110.

${ }^{41}$ Petrônio, Satyricon, 131, 8: Mobilis aestiuas platanus diffuderat umbras/ et bacis redimita Daphne tremulaeque cupressus/ et circum tonsae trepidanti uertice pinus./ Has inter ludebat aquis errantibus amnis/ spumeus, et querulo uexabat rore lapillos./Dignus amore locus: testis siluestris aedon/ atque urbana Procne, quae circum gramina fusae/ et molles uiolas cantu sua rura colebant (trad. nossa).

${ }^{42}$ Cf. Connors, 1998, p. 71-72.
} 
eu preste meu culto a você"', ${ }^{43}$ Essa devoção à amada assemelha-se ao tópos do seruitium amoris, segundo o qual o amante elegíaco torna-se "escravo do amor, naturalmente, e da mulher amada. É esse o motivo central, em torno do qual giram todas as manifestações do amor elegíaco". ${ }^{44}$ Isso é reforçado ainda pelo fato de Encólpio/ Polieno chamar Circe de domina na mensagem que lhe escreve, ${ }^{45}$ termo tipicamente empregado pelo amante elegíaco para se dirigir à amada.

Porém, na elegia o amor geralmente não se realiza em razão da duritia da mulher, que se recusa a ceder ao amante e impõe-lhe obstáculos, fazendo com que ele sofra por um amor não correspondido: "A mulher (ou o puer [garoto], no caso da poesia pederástica) deve ser indiferente, relutante, instável ou desleal, para que o poeta possa ter material para ser capaz de colocar em verso seus sofrimentos amorosos". "No Satyricon, por sua vez, Circe não se opõe a Encólpio/ Polieno, e inicialmente não há obstáculos para a efetuação do amor. Entretanto, ele igualmente não se realiza, mas devido à impotência sexual da personagem.

${ }^{43}$ Petrônio, Satyricon, 127, 3: Immo, inquam, ego per formam tuam te rogo, ne fastidias hominem peregrinum inter cultores admittere. Inuenies religiosum, si te adorari permiseris (trad. S. Bianchet, p. 245).

${ }^{44}$ Cf. Fedeli, 1991, p. 111: Schiavo d'amore, naturalmente, e della donna amata. È questo il motivo centrale, attorno a cui ruotano tutte le manifestazioni dell'amore elegiaco (trad. nossa). ${ }^{45}$ Petrônio, Satyricon, 130, 1: [Polyaenos Circae salutem] "Fateor me, domina, saepe pecasse". ${ }^{46}$ Cf. Garbarino, apud Konstan, 1994, p. 153: The woman (or the "puer" [boy], in the case of pederastic poetry) must be indifferent, reluctant, fickle and faithless, so that the poet may have the material to be able to pour out in verse his amorous sufferings (trad. nossa).

${ }^{47}$ Se considerado o intertexto épico da Odisseia (10, 293-301), a impotência de Encólpio/ Polieno diante de sua Circe constitui uma verdadeira paródia do episódio de união de Odisseu com a feiticeira Circe. Ora, diante da ameaça de perder sua virilidade, Odisseu, antes de se unir a Circe, previne-se por meio de um antídoto oferecido por Hermes e, além disso, faz com que a feiticeira pronuncie um juramento. Uma análise detalhada desse episódio e da imagem de Circe na Odisseia é empreendida por Assunção (2011, p. 153-176), que afirma em p. 157: E é não apenas o "móly" (planta mágica, fornecida por Hermes, que serve de contra-veneno ao "kykeón” da ninfa) mas também uma instrução do deus, o que, no relato de Ulisses, justifica que ele aceite partilhar o leito da ninfa (mas apenas após ela ter jurado que não o tornaria covarde e não viril, ainda segundo uma orientação de Hermes). É interessante notar que a feiticeira Circe, personagem repleta de ambiguidades na Odisseia, antes de ser aludida de forma paródica no episódio petroniano, já havia sido retomada no contexto épico da Eneida de Virgílio e das Metamorfoses de Ovídio. A esse respeito, Segal (1968, p. 419-442) realiza uma cuidadosa comparação dos traços 
Outro aspecto essencial no plano composicional do Satyricon é que Encólpio, após os episódios da Cena Trimalchionis, passa a interferir na narrativa por meio da inserção de suas produções poéticas, ou seja, o narrador em primeira pessoa torna-se também poeta. Nesse sentido, notase que, nos episódios dos amores com Circe, ele, logo ao início, assume a persona de um poeta elegíaco. E uma das características do amante elegíaco é dedicar versos à puella que deseja conquistar, na medida em que não possui recursos para lhe dar caros presentes. ${ }^{48}$ Sob esse aspecto, "a poesia elegíaca é programaticamente uma poesia de cortejo". "Ela é vista como um meio de obtenção dos favores da puella, cuja duritia os apaixonados tentam abrandar ao prometer imortalidade e fama por meio de seus versos. ${ }^{50}$ Isso fica marcado no Satyricon pelo fato de Encólpio/ Polieno, ao se encontrar com Circe pela primeira vez, dedicar-lhe versos em dístico elegíaco, os quais ela aprecia: "Encantada com esses versos, ela sorriu para mim de modo tão meigo que parecia a lua exibindo sua face em plenitude, sem qualquer nuvem".

Também a imagem de um jovem capturado e incendiado pelo amor consiste em um tópos da poesia lírico-elegíaca. Nos dois últimos versos da inserção poética de Encólpio/ Polieno, merece destaque a seleção de vocábulos do campo semântico do fogo, como flammifero calore: "É esta a verdadeira Dânae. Apenas tente tocar o corpo dela/ e seus membros imediatamente irão escoar-se em inflamado calor". ${ }^{52}$ Segundo Connors,

assumidos pela personagem em Homero, Virgílio e Ovídio, a fim de verificar, em p. 419, "como os dois poetas latinos transmutaram o material homérico para novos propósitos de seu interesse" (how the two Latin poets transmuted the Homeric material for new purposes of their own - trad. nossa). Diferentemente, no entanto, a retomada petroniana parece subverter parodicamente o modelo épico da Odisseia, uma vez que Encólpio/ Polieno, que não é astuto nem heroico, será acometido pela impotência sexual, à qual Odisseu havia escapado.

${ }^{48}$ Ovídio, Ars Amatoria, II, 273-276: Quid tibi praecipiam teneros quoque mittere uersus?/ Ei mihi! non multum carmen honoris habet./ Carmina laudantur, sed munera magna petuntur;/ Dummodo sit diues, barbarus ipse placet. - "Por que te instruirei a enviar também brandos versos?/ Ai de mim! Poemas não têm muita estima./ Louvam-se os poemas, mas pedem-se maiores presentes;/ desde que seja rico, até o bárbaro agrada" (trad. nossa). ${ }^{49}$ Cf. Fedeli, apud Giangrande, 1991, p. 64: La poesia elegiaca è programmaticamente una poesia di corteggiamento.

${ }^{50}$ Cf. Trevizam, 2003, p. 110.

${ }^{51}$ Petrônio, Satyricon, 127, 1: Delectata illa risit tam blandum, ut uideretur mihi plenum os extra nubem luna proferre (trad. S. Bianchet, p. 245).

${ }^{52}$ Petrônio, Satyricon, 126, 18: Haec uera est Danae. Tempta modo tangere corpus,/ iam tua 
é como se Encólpio estivesse prevendo no poema que irá arder de amores por Circe, ${ }^{53}$ o que é reforçado pela conclusão desta, ao afirmar que sempre surge uma chama/ excitação ( $f a x)$ entre os nomes de Circe e Polieno.

Inclusive, já na descrição inicial de Circe evidenciam-se os ardores que ela irá provocar. A personagem é introduzida na narrativa por meio de uma ecfrase, ${ }^{55}$ que a aproxima de uma obra de arte e culmina com sua comparação ao mármore de Paros: Parium marmor extinxerat. ${ }^{56}$ Segundo Connors, ${ }^{57}$ a passagem é similar à descrição de Glícera, feita por Horácio: urit me Glycerae nitor/ splendentis Pario marmore purius. ${ }^{58}$ Todavia, enquanto Glícera, brilhando como o mármore, queima o eu-poético horaciano, Circe metaforicamente extingue o brilho do próprio mármore, ou seja, o ofusca. O emprego do termo extinxerat é bastante significativo, uma vez que, no contexto da narrativa petroniana, ele gera humor. Circe faz Encólpio/ Polieno arder de amores, mas quando eles se unem amorosamente, Encólpio é incapaz de consumar o ato amoroso: o poder de Circe para "extinguir", na verdade, "extinguiu" as chamas da paixão. ${ }^{59}$ De certo modo, isso já havia sido antecipado nos próprios versos de Encólpio dedicados a Circe, uma vez que ele a compara a Dânae. Ora, segundo a tradição mítica, Dânae concebeu Perseu sendo ainda virgem: foi fecundada por Júpiter metamorfoseado em chuva de ouro. ${ }^{60}$ Dessa forma, a não ocorrência de relação sexual no mito antecipa sua não consumação também no Satyricon, mas devido à impotência de Encólpio.

\footnotetext{
flammifero membra calore fluent (trad. S. Bianchet, p. 245).

${ }^{53}$ Cf. Connors, 1998, p. 70.

${ }^{54}$ Petrônio, Satyricon, 127, 7: Nec sine causa Polyaenon Circe amat: semper inter haec nomina magna fax surgit.

${ }^{55}$ É bem marcante o fato de a descrição de Circe iniciar-se exatamente pela menção de seus cabelos (Satyricon, 126, 15). A valorização dos cabelos da amada é tema bastante presente na poesia lírico-elegíaca. A elegia I, 14 dos Amores de Ovídio, por exemplo, consiste em uma repreensão da amada por ter queimado os seus cabelos ao tentar frisá-los. No Satyricon $(109,9)$, inclusive, essa temática foi anteriormente empregada (ainda que de modo paródico e ridículo) na elegia de Eumolpo, em que se lamenta a "morte" dos cabelos de Gitão e de Encólpio.

${ }^{56}$ Petrônio, Satyricon, 126, 18.

${ }^{57}$ Cf. Connors, 1998 , p. 70.

${ }^{58}$ Horácio, Carmina, I, 19, 5-6: "Queima-me o brilho da reluzente/ Glícera, mais claro que o mármore de Paros” (trad. nossa).

${ }^{59}$ Cf. Connors, 1998, p. 71.

${ }^{60}$ Ovídio, Metamorfoses, 4, 611; Higino, 63, 1.
} 
Assim, a princípio, a impotência de Encólpio/ Polieno parece constituir, no contexto da obra, uma inversão paródica por meio do rebaixamento de seus modelos, tanto épico quanto elegíaco. Diferentemente de Odisseu, que, advertido por Hermes, soube se proteger dos encantamentos de Circe graças à droga que o deus lhe oferecera e, dessa forma, pôde-se unir a Circe sem perder sua virilidade, ${ }^{61}$ Polieno/ Encólpio falha na execução dos atos sexuais e é acometido pela impotência. ${ }^{62}$ Diferentemente do amante elegíaco, que sofre a recusa da dura puella e, por isso, não efetua os atos amorosos, Encólpio não concretiza seus desejos pela falha de seu próprio "equipamento": "Não fui eu que falhei, mas meu equipamento". ${ }^{63}$

Todavia, é interessante observar que o que, a princípio, poderia parecer uma inversão paródica do gênero elegíaco efetuada pela narrativa de ficção em prosa do Satyricon, na verdade, já havia sido parodiado pela própria elegia ovidiana. Evidência disso é o poema III, 7 dos Amores, que aborda exatamente a impotência do amante elegíaco em meio à noite de amores com sua puella, elegia que pode ter sido um dos modelos principais do episódio da impotência de Encólpio. ${ }^{64}$

A elegia inicia-se com a expressão de desdém do eu-poético em relação à amada, como se diminuir as qualidades da moça pudesse

\footnotetext{
${ }^{61}$ Cf. Connors, 1998, p. 42.
}

${ }^{62}$ Insucessos desse tipo tornam Encólpio, segundo Fedeli, um "Odisseu imperfeito": Sendo, porém, um herói degradado, o protagonista do romance petroniano será, sim, em seu agir condicionado pelo modelo, mas terminará por inverter os êxitos dos episódios paralelos (Fedeli, 2010, p. 375).

${ }^{63}$ Petrônio, Satyricon, 130, 4: Non me sed instrumenta peccasse (trad. S. Bianchet, p. 253).

${ }^{64}$ Baeza Angulo (1989) efetua um levantamento de possíveis hipo e hipertextos da elegia III, 7 de Ovídio (ainda que se aproxime da busca de "fontes" no sentido da Quellenforschung, o artigo tem a vantagem de ser bem documentado). Assim, observa-se que o tema do da impotência está presente em alguns autores de epigramas gregos, como Filodemo (A. P. 11, 30), Automedonte (A. P. 5, 129) e Escitino (A. P. 12, 232), e também em Catulo (67, 20-2) e Tibulo (I, 5, 39-42). $\mathrm{O}$ estudioso destaca, porém, que na elegia ovidiana o assunto é tratado mais abertamente do que nos dois poetas latinos que o antecedem. Em relação aos epigramas gregos citados, é interessante notar que, assim como na elegia ovidiana, é mencionada a "morte do membro viril" e a "velhice antecipada do jovem amante"; que poderiam, portanto, ser considerados, na perspectiva de Achcar (1994), tópoi de um gênero "impotência do amante". Por sua vez, no caso do Satyricon, ainda que se façam presentes esses tópoi helenísticos que foram apropriados pela elegia latina, notam-se outras semelhanças temáticas e lexicais em relação à elegia III, 7, o que permitiria pensar em um procedimento de alusão. 
minimizar ou justificar a impotência do amante elegíaco: "Ao menos não é bela, ao menos não é moça bem cuidada, ao menos, julgo, não foi muito rogada por meus desejos!". ${ }^{65}$ No Satyricon, de forma semelhante, logo após a impotência de Encólpio, Circe lança uma série de perguntas - primeiro ao amante, ${ }^{66}$ depois à escrava $-{ }^{67}$ a respeito de sua aparência, como que para se defender de uma possível reação desdenhosa por parte de Encólpio, como ocorrera na elegia.

O narrador, por sua vez, coberto de vergonha (perfusus rubore), justifica a impotência por ter sido atingido por um feitiço: "Por favor, minha rainha, não difame meus infortúnios. Eu fui contaminado por um feitiço". ${ }^{68}$ Igualmente, na elegia ovidiana, a possível causa da desgraça do eu-poético é a magia:

Acaso meu corpo se enfraquece, amaldiçoado por feitiços da

Tessália? Acaso ervas e encantamentos afetam o infeliz, ou uma bruxa gravou meu nome em cera vermelha e fincou fina agulha no meio do meu fígado?

Por encantamento afetada, Ceres desfaz-se em erva estéril, por encantamento afetadas, secam as fontes de água, caem dos carvalhos as glandes, e das vinhas a uva encantada, e, sem mover, caem os frutos.

O que impede que também minha vara se entorpeça pela magia? Talvez por isso meu corpo tornou-se impotente.

${ }^{65}$ Ovídio, Amores, III, 7, 1-2: At non formonsa est, at non bene culta puella,/ at, puto, non uotis saepe petita meis! (trad. nossa)

${ }^{66}$ Petrônio, Satyricon, 128, 1: "Quid est" inquit; "numquid te osculum meum offendit? Numquid spiritus ieiunio marcet? Numquid alarum negligens sudor?” - "Qual o problema?”, ela disse, "por acaso meu beijo ofendeu você? Por acaso meu hálito está ressecado por causa do jejum? Por acaso seria o suor de minhas axilas que está com mau cheiro?" (trad. S. Bianchet, p. 247)

${ }^{67}$ Petrônio, Satyricon, 128, 3: "Dic, Chrysis, sed uerum: numquid indecens sum? Numquid incompta? Numquid ab aliquo naturali uitio formam meam excaeco? Noli decipere dominam tuam. Nescio quid peccauimus”. - "Diga-me, Críside, mas diga a verdade: por acaso eu sou feia? Por acaso estou despenteada? Por acaso tenho a minha beleza ofuscada por algum defeito de nascença? Não engane sua dona. Não sei que erro cometemos" (trad. S. Bianchet, p. 249).

${ }^{68}$ Petrônio, Satyricon, 128, 2: "Quaeso", inquam, "regina, noli suggillare miserias. Veneficio contactus sum” (trad. S. Bianchet, p. 247).

${ }^{69}$ Ovídio, Amores, III, 7, 27-36: Num mea Thessalico languent deuota ueneno/ corpora? num misero carmen et herba nocent,/ sagaue poenicea defixit nomina cera/ et medium tenuis in iecur egit acus?/ Carmine laesa Ceres sterilem uanescit in herbam;/ deficiunt laesi carmine 
O termo usado para designar o membro viril do amante elegíaco é neruos, que traduzimos como "vara", para manter o uso metafórico e, além disso, prolongar as imagens vegetais e agrícolas presentes nos versos anteriores. Ora, precisamente o mesmo vocábulo é empregado no Satyricon para se referir ao membro viril de Encólpio, que falha em suas funções: Circe insere seu amante na categoria dos "homens sem nervos" (sine neruis homines, Sat., 129, 5), mas crê que Encólpio receberá seus nervos de volta (recipies, inquam, neruos tuos, Sat. 129, 8). A velha Proselenos consegue reerguer os nervos de Encólpio e fazê-los encherem sua mão (nerui paruerunt imperio manusque aniculae ingenti motu repleuerunt, Sat. 131, 6), ${ }^{70}$ mas, persistindo a impotência, pergunta-lhe "que feiticeiras comeram seus nervos?" (Quae striges comederunt nervos tuos?, Sat. 134, 1). A impotência, além disso, é igualada à perda de virilidade e associada à morte do membro viril ou à antecipação da velhice do jovem amante elegíaco, que não se mostra nem iuuenis, nem uir, nem uiuus:

Que velhice alcançarei, se é que alcançarei,

quando a própria juventude falta às suas funções?

Ai! envergonho-me dos anos! Para que ser jovem e homem?

A amada não me sente nem jovem nem homem!

$[\ldots]$

Ela pôde mover os pesados carvalhos, o duro diamante

e as surdas rochas com suas meiguices.

Decerto era digna de mover os vivos e os viris:

mas, então, nem eu vivia nem era homem como antes. ${ }^{71}$

\footnotetext{
fontis aquae, / ilicibus glandes cantataque uitibus uva/ decidit, et nullo poma mouente fluunt./ Quid uetat et neruos magicas torpere per artes?/ Forsitan inpatiens sit latus inde meum (trad. nossa).

${ }^{70}$ Assim como a velha tentara estimular o membro viril de Encólpio com o movimento das mãos (admotis manibus, Sat. 131, 5), também a amada do eu-poético elegíaco o fizera, mas sem sucesso: Hanc etiam non est mea dedignata puella/ molliter admota sollicitare manu (Amores, III, 7, 73-74). - "A ela, minha amada não desdenhou até incitar/ brandamente com o movimento da mão" (trad. nossa). Destaque-se o fato de que a expressão usada na elegia é a mesma, admota manu.

${ }^{71}$ Ovídio, Amores, III, 7, 17-20 e 57-60: Quae mihi uentura est, siquidem uentura, senectus,/ cum desit numeris ipsa iuuenta suis?/ A! pudet annorum! quo me iunenemque uirumque?/ Nec iuuenem nec me sensit amata uirum! e Illa graues potuit quercus adamantaque durum / surdaque blanditiis saxa mouere suis./ Digna monere fuit certe uinosque uirosque:/ sed neque tum uixi nec uir, ut ante, fui (trad. nossa).
} 
De maneira similar, Encólpio não se entende por homem (uirum) e considera os funerais (funerata est) de seu membro: "Acredite em mim, parceiro, acho que não sou homem, não me sinto homem. Aquele famoso membro de meu corpo, com o qual outrora eu era um Aquiles, está pronto para receber as últimas homenagens". ${ }^{72}$

Diante da persistência da impotência, Encólpio, enfurecido, compõe um poema metricamente inverso à épica (visto que em versos sotádicos, de ritmo anapéstico), ${ }^{73}$ mas que evoca a poesia épica por meio do vocabulário (ter, bipennem, ferrum, mortifero, por exemplo). O caráter paródico em relação à poesia sublime, que é aludida e rebaixada, evidencia-se ainda pelo fato de tais versos descreverem metaforicamente o estado do membro viril da personagem: ele estava "subitamente mais mole do que talo de tirso" e foi considerado um "inverno mais frio do que o gelado medo". ${ }^{74}$ É interessante notar que as imagens usadas aproximam-se daquelas presentes na descrição do membro viril inativo do amante elegíaco ovidiano. Assim, além de um intertexto épico, é possível identificar um intertexto elegíaco:

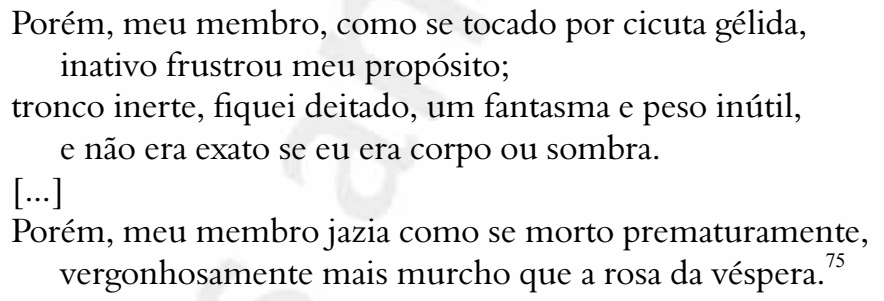

A ideia de frieza também se manifesta em "cicuta gélida" (gelida cicuta) e, em ambos os casos, o frio expressa a insensibilidade e a inércia do membro viril da personagem. Semelhança mais marcante é o uso do mesmo adjetivo no comparativo, tendo como complemento uma metáfora vegetal: languidior coliculi thyrso e languidiora rosa hesterna. ${ }^{76}$ Dessa forma, transferem-

\footnotetext{
${ }^{72}$ Petrônio, Satyricon, 129, 1: "Crede mihi, frater, non intellego me uirum esse, non sentio. Funerata est illa pars corporis, qua quondam Achilles eram” (trad. S. Bianchet, p. 249).

${ }^{73}$ Cf. Bianchet, 2012, p. 116-117.

${ }^{74}$ Petrônio, Satyricon, 132, 8: Languidior coliculi repente thyrso e metu frigidior rigente bruma (trad. S. Bianchet, p. 257).

${ }^{75}$ Ovídio, Amores, III, 7, 13-6 e 65-6: Tacta tamen ueluti gelida mea membra cicutal segnia propositum destituere meum;/ truncus iners iacui, species et inutile pondus, / et non exactum, corpus an umbra forem. e Nostra tamen iacuere uelut praemortua membra/ turpiter hesterna languidiora rosa (trad. nossa).

${ }^{76}$ Em Catulo, 67, v. 21, ao se referir a um marido que não tocou sua esposa,
} 
se ao membro viril as qualidades de mole e murcho, características das plantas. No trecho ovidiano, destaca-se também o vocabulário do campo semântico da morte, como corpus/ umbra, iacuere, praemortua.

Outro elemento que aproxima a impotência do amante elegíaco ovidiano à de Encólpio consiste no discurso que ambos dirigem ao membro viril:

O que você me diz, vergonha de todos os homens e deuses? Nem sequer pronunciar o seu nome como parte das coisas sérias é justo. Eu fiz por merecer que você me arrastasse para os infernos, a mim que estava no céu? Eu fiz por merecer que você retirasse de mim os prósperos anos de total vigor e impusesse o cansaço da terceira idade? Por favor, dê-me novamente uma rápida amostra do seu vigor. ${ }^{77}$

"Por que não jazes aí desonrada, pior parte de mim?

Assim fui capturado antes por tuas promessas.

Enganas teu senhor; por tua causa, pego desarmado, sofri tristes perdas com grande vergonha". ${ }^{78}$

Em ambos os casos, observa-se que o narrador/ eu-poético repreende seu membro viril, causa de engano, falsas expectativas e, principalmente, vergonha (pudor) devido à impotência. Esse tom de censura gera humor, visto que se empreende uma séria reprimenda contra uma parte do corpo que não é associada à austeridade. É interessante notar que, no Satyricon, o narrador ainda justifica o fato de ter dirigido palavras ao seu membro viril. Isso se dá ao serem evocados exemplos - tanto da literatura elevada, quanto da própria vida - nos quais foi permitido dirigir-se a alguma parte do

observa-se o emprego do mesmo adjetivo no comparativo e o uso de uma metáfora vegetal para o membro viril: Languidior tenera cui pendens sicula beta - "A quem a pendente 'adaga' era mais mole que tenra acelga". O interessante na elegia ovidiana e no Satyricon é que o termo se refere ao membro do próprio eu-poético, e não de outrem.

${ }^{77}$ Petrônio, Satyricon, 132, 9-10: Quid dicis", inquam, "omnium hominum deorumque pudor? Nam ne nominare quidem te inter res serias fas est. Hoc de te merui, ut me in caelo positum ad inferos traheres? ut traduceres annos primo florentes uigore, senectaeque ultimae mihi lassitudinem imponeres? Rogo te, mihi apodixin defunctoriam redde (trad. S. Bianchet, $\mathrm{p}$. 257 e 259).

${ }^{78}$ Ovídio, Amores, III, 7, 69-72: Quin istic pudibunda iaces, pars pessima nostri?/ Sic sum pollicitis captus et ante tuis;/ tu dominum fallis, per te deprensus inermis/ tristia cum magno damna pudore tuli (trad. nossa). 
corpo. ${ }^{79}$ Assim, a apresentação de exemplos da literatura elevada possibilita a interpretação do discurso de Encólpio como uma inversão paródica dos gêneros épico e trágico.

Finalmente, nota-se no episódio o emprego de um vocabulário tipicamente bélico para se referir à situação: o amante elegíaco foi capturado por promessas (pollicitis captus) e pego desarmado (deprensus inermis). Similarmente, no Satyricon, Encólpio afirma que, "soldado preparado para a batalha, não tive armas para combater". ${ }^{80}$ Ora, os símiles bélicos frequentemente usados no gênero elegíaco para designar os atos amorosos ${ }^{81}$ adquirem, nesses exemplos, caráter irônico.

\section{Considerações finais}

Com base nas análises aqui realizadas, pretendeu-se demonstrar que os episódios da separação de Encólpio e Gitão e dos amores de Circe e Encólpio/ Polieno se constituem a partir de tópoi e modelos da poesia lírico-elegíaca, ainda que tópoi e intertextos épicos também se façam presentes. Ao compor versos no metro do dístico elegíaco, Encólpio assume uma persona elegíaca, seja a do amante apaixonado, seja a de um exilado. É interessante notar que essa persona não se limita aos trechos em verso e extrapola para a narrativa em prosa, de modo que o narrador-

\footnotetext{
${ }^{79}$ Petrônio, Satyricon, 132, 13-14: Aut quid est quod in corpore humano uentri male dicere solemus aut gulae capitique etiam, cum saepius dolet? Quid? Non et Vlixes cum corde litigat suo, et quidam tragici oculos suos tanquam audientes castigant? Podagrici pedibus suis male dicunt, chiragrici manibus, lippi oculis, et qui offenderunt saepe digitos, quicquid doloris habent, in pedes deferunt. - "Ou melhor, por que é que, em relação ao corpo humano, nós costumamos reclamar da barriga, ou da boca, ou até mesmo da cabeça, quando elas muito frequentemente nos causam dor? Por quê? Não disputa Ulisses com seu coração, e alguns trágicos não repreendem seus olhos, como se eles os ouvissem? Os que têm gota nos pés reclamam dos pés, os que têm nas mãos reclamam das mãos, os remelentos reclamam dos olhos e os que já esbarraram seus dedos muitas vezes acusam seus pés de qualquer dor que sentem" (trad. S. Bianchet, p. 259). ${ }^{80}$ Petrônio, Satyricon, 130, 4: Paratus miles arma non habui (trad. S. Bianchet, p. 253). ${ }^{81}$ Fedeli (1991, p. 110) comenta sobre o poeta elegíaco que "A sua é uma militia Amoris e os seus acampamentos são aqueles de Vênus: toda uma série de vocábulos da linguagem militar penetra na linguagem erótica e perpassa as várias fases do amor" [La sua è una "militia Amoris" e i suoi accampamenti sono quelli di Venere: tutta una serie di vocaboli del linguaggio militare penetra nel linguaggio erotico e scandisce le varie fasi dell'amore (trad. nossa).].
} 
personagem passa a viver e enxergar o mundo segundo um referencial literário.

Esse procedimento tem duas implicações na obra. Primeiramente, a riqueza genérica presente no Satyricon ressalta o aspecto plasmático das narrativas de ficção em prosa, que parece se definir como gênero justamente ao realizar transgressões genéricas. Ao mesmo tempo, ao explorar diversos tópoi da tradição literária, empreende-se uma reflexão sobre a literatura e a própria estrutura do romance, destacando seu caráter metaliterário. Em segundo lugar, no contexto do Satyricon, os tópoi e modelos da tradição literária são ressignificados, na maior parte das vezes, de modo paródico ou irônico. Assim, a atribuição de personae de diferentes gêneros literários a Encólpio e, sobretudo, sua inversão/ subversão ao longo da narrativa evidenciam a ingenuidade do narrador-personagem, que, mais que um narrador "mitomaníaco", é "literomaníaco", pois se comporta segundo padrões e tópoi dos mais variados gêneros literários.

\section{Referências}

ACHCAR, F. Lírica e lugar-comum: alguns temas de Horácio e sua presença em português. São Paulo: Edusp, 1994.

ASSUNÇÃO, T. R. Infidelidades veladas: Ulisses entre Circe e Calipso na "Odisseia". Nuntius antiquus, Belo Horizonte, vol. 7, n. 2, p. 153-176, 2011.

BAEZA ANGULO, E. F. Ovidio, "Amores” III, 7. Faventia, Barcelona, vol. 11, n. 1, p. 25-58, 1989.

BIANCHET, S. M. G. B. Irregularidades métricas e rebaixamento do poético no "Satyricon", de Petrônio. Aletria, Belo Horizonte, vol. 22, n. 1, p. 111-118, 2012. BIANCHET, S. M. G. B. Introdução. In: PETRÔNIO. Satyricon. Trad. Sandra Braga Bianchet. Belo Horizonte: Crisálida, 2004, p. 7-11.

BRANDÃO, J. L. A invenção do romance. Brasília: Editora Universidade de Brasília, 2005.

CATULLE. Poésies. Texte établi et trad. par G. Lafaye. Paris: Les Belles Lettres, 1949. CONNORS, C. Petronius the poet: verse and literary tradition in the "Satyricon". Cambridge: Cambridge University Press, 1998.

CONTE, G. B. The hidden author: an interpretation of Petronius's "Satyricon". Trans. Elaine Fantham. Berkeley: University of California Press, 1996.

FEDELI, P. O romance. In: CAVALLO, G.; FEDELI, P; GIARDINA, A. O espaço literário da Roma antiga: a produção do texto. Trad. D. Carrara e F. Moura. Belo Horizonte: Tessitura, 2010, p. 361-392.

FEDELI, P. Bucolica, lirica, elegia. In: CITRONI, M. et alii (org.). La poesia latina: forme, autori, problemi. Roma: La Nuova Italia Scientifica, 1991. 
GIANGRANDE, G. Topoi ellenistici nell' "Ars Amatoria”. In: GALLO, I.; NICASTRI, L. (org.). Cultura poesia ideologia nell'opera di Ovidio. Napoli: Edizioni Scientifiche Italiane, 1991, p. 61-98.

HYGIN. Fables. Texte établi et trad. par J.-Y. Boriand. Paris: Les Belles Lettres, 2003. HORÁCIO. Epistula ad Pisones. Trad. e org. Júlia B. C. Avellar, Sandra Bianchet, Bruno F. S. Maciel e Darla G. Monteiro. Horizonte: FALE/ UFMG/Viva Voz, 2013. Disponível em: < http://www.letras.ufmg.br/vivavoz/index. asp?path=no1vol1julho2004.asp\&title=Downloads. $>$ Acesso em 29 de julho de 2014. HORACE. Odes et épodes. Texte établi et trad. par F. Villeneuve. Paris: Les Belles Lettres, 1954.

KONSTAN, D. Sexual symmetry: love in the ancient novel and related genres. Princeton: Princeton University Press, 1994.

LEÃO, D. F. O "Satyricon" de Petrónio: malhas de acaso e descaso. In: PEREIRA, V. S.; CURADO, A. L. (org.). A Antiguidade Clássica e nós: herança e identidade cultural. Braga: Universidade do Minho, 2006, p. 227-241.

ONELLEY, G. B. A ideologia aristocrática nos "Theognidea". Niterói: Editora da UFF, 2009.

OVIDE. L'art d'aimer. Texte établi et trad. par H. Bornecque. Paris: Les Belles Lettres, 1951.

OVIDE. Les Amours. Texte établi et trad. par H. Bornecque. Paris: Les Belles Lettres, 1952.

OVIDE. Les Héroïdes. Trad. par Émile Ripert. Paris: Garnier Frères, 1932.

OVIDE. Les Métamorphoses. Texte établi et trad. par G. Lafaye. Paris: Les Belles Lettres, 1957.

OVIDE. Tristes. Texte établi et trad. par J. André. Paris: Les Belles Lettres, 2008.

PETRÔNIO. Satyricon. Trad. Sandra Braga Bianchet. Belo Horizonte: Crisálida, 2004.

PÉTRONE. Le Satiricon. Texte établi et trad. par A. Ernout. Paris: Les Belles Lettres, 1950.

PROPÉRCIO. Elegias de Sexto Propércio. Organização e trad. Guilherme Gontijo Flores. Belo Horizonte/ São Paulo: Autêntica, 2014.

SEGAL, C. Circean temptations: Homer, Vergil, Ovid. Transactions and Proceedings of the American Philological Association. Baltimore, vol. 99, p. 419-442, 1968.

TREVIZAM, M. A elegia erótica romana e a tradição didascálica como matrizes compositivas da "Ars Amatoria" de Ovídio. Dissertação de mestrado inédita. Campinas: Instituto de Estudos da Linguagem da Unicamp, 2003. 
